Open Access

\title{
Modeling and forecasting exchange rate volatility in Bangladesh using GARCH models: a comparison based on normal and Student's t-error distribution
}

S. M. Abdullah ${ }^{1 *}$, Salina Siddiqua ${ }^{2}$, Muhammad Shahadat Hossain Siddiquee ${ }^{1,3}$ and Nazmul Hossain ${ }^{1}$

* Correspondence:

abdullahsonnet@gmail.com

'Department of Economics, University of Dhaka, Dhaka, Bangladesh

Full list of author information is available at the end of the article

\begin{abstract}
Background: Modeling exchange rate volatility has remained crucially important because of its diverse implications. This study aimed to address the issue of error distribution assumption in modeling and forecasting exchange rate volatility between the Bangladeshi taka (BDT) and the US dollar (\$).

Methods: Using daily exchange rates for 7 years (January 1, 2008, to April 30, 2015), this study attempted to model dynamics following generalized autoregressive conditional heteroscedastic (GARCH), asymmetric power ARCH (APARCH), exponential generalized autoregressive conditional heteroscedstic (EGARCH), threshold generalized autoregressive conditional heteroscedstic (TGARCH), and integrated generalized autoregressive conditional heteroscedstic (IGARCH) processes under both normal and Student's t-distribution assumptions for errors.

Results and Conclusions: It was found that, in contrast with the normal distribution, the application of Student's $t$-distribution for errors helped the models satisfy the diagnostic tests and show improved forecasting accuracy. With such error distribution for out-of-sample volatility forecasting, $\operatorname{AR}(2)-\mathrm{GARCH}(1,1)$ is considered the best.
\end{abstract}

Keywords: Exchange rate, Volatility, ARCH, GARCH, Student's t, Error distribution JEL codes: C52, C580, E44, E47

\section{Background}

In an era of globalization and of flexible exchange rate regimes in most economies, an analysis of foreign exchange rate volatility has become increasingly important among academics and policymakers in recent decades. Volatile exchange rates are likely to affect countries' international trade flow, capital flow, and overall economic welfare (Hakkio, 1984; De Grauwe, 1988; Asseery \& Peel, 1991). It is also crucially important to understand exchange rate behavior to design proper monetary policy (Longmore \& Robinson, 2004). As a result, researchers, stakeholders, and policymakers are very interested in analyzing and learning about the nature of exchange rate volatility, which

(c) The Author(s). 2017 Open Access This article is distributed under the terms of the Creative Commons Attribution 4.0 International License (http://creativecommons.org/licenses/by/4.0/), which permits unrestricted use, distribution, and reproduction in any medium, provided you give appropriate credit to the original author(s) and the source, provide a link to the Creative Commons license, and indicate if changes were made. 
can help to design policies to mitigate the adverse effects of exchange rate volatility on important economic indicators.

Accordingly, beginning with Engle's (1982) autoregressive conditional heteroscedasticity (ARCH) model, several models have already been developed to model volatility. Different models have aimed to capture different features of volatility. For example, while some models are only used to model "volatility clustering," ${ }^{1}$ others are used to capture the "leverage effect." ${ }^{2}$ However, it is widely recognized among researchers that because of increased kurtosis, along with an increase in data frequency, the rate of return in financial or macroeconomic variables as exchange rates might have a levy distribution, or a fat tail (Mandelbrot, 1963). Thus, volatility models should not be considered under the general normality assumption for errors, because if the errors are not thus, then volatility forecasting based on such models will be misleading. The current study makes an effort to appropriately model and forecast the volatility of the exchange rate return of the taka against the US dollar, taking into account the issue of error distribution assumption.

The rest of this paper is organized as follows. Literature review presents a review of previous literature that has attempted to model and forecast exchange rate volatility using various $\mathrm{ARCH}$ and generalized autoregressive conditional heteroscedasticity (GARCH) models. Methods describes the data and the theoretical methodology. Estimation results and findings analyzes and compares the results of different $\mathrm{ARCH}$ and GARCH models. Forecasting exchange rate return volatility is discussed in Volatility Forecasting, and Conclusion concludes the paper.

\section{Literature review}

Modeling exchange rate volatility has remained crucially important because of its diverse implications. Bala and Asemota (2013) examined exchange rate volatility using GARCH models. They used monthly exchange rate return series for the naira (Nigerian currency) against the US dollar (\$), British pound, and euro. To compare the estimates, various GARCH models were estimated with and without volatility breaks. It was revealed that most of the models rejected the existence of a leverage effect, except for those with volatility breaks. Since it was observed that results improved when the volatility models considered breaks, incorporating significant events in the GARCH models was suggested. Clement and Samuel (2011) also aimed to model Nigerian exchange rate volatility. They used the monthly exchange rate of the naira against the US dollar and British pound for the period from 2007 to 2010. They found that the exchange rate return series was nonstationary and that the series residuals were asymmetric. Since return volatility was found to be persistent, the study recommended further investigation of the impact of government policies on foreign exchange rates.

Rofael and Hosni (2015) aimed to forecast and estimate exchange rate volatility in Egypt using ARCH and state space (SS) models. Using daily exchange rate data covering about 10 years, they found volatility clustering in Egypt's exchange rate returns, as well as a risk of mismatch between exchange rates and the stock market. Similar results were obtained by Choo, Loo, and Ahmad (2002), who used GARCH model variants to capture the exchange rate volatility dynamics of the Malaysian ringgit (RM) against the pound sterling. They used daily data for the period from 1990 to 1997 and concluded that the volatility of the RM-sterling exchange rate was persistent. For within-sample 
modeling, they found the GARCH models to be the best, while for forecasting, almost all the GARCH - in - mean models outperformed ordinary GARCH models.

Dhamija and Bhalla (2010) argued that conditionally heteroscedastic models can be used to model exchange rate volatility. They found that integrated generalized autoregressive conditional heteroscedsticity (IGARCH) and threshold generalized autoregressive conditional heteroscedsticity (TGARCH) models performed better than others when forecasting the volatility of five daily currencies: the British pound, German mark, Japanese yen, Indian rupee and Euro. Later, Ramasamy and Munisamy (2012) concluded that GARCH models were efficient for predicting exchange rate volatility. They examined the daily exchange rates of four currencies-the Australian dollar, Singapore dollar, Thai bhat, and Philippine peso-using GARCH, Glostern - Jagannathan - Runkle GARCH (GJR-GARCH), and exponential generalized autoregressive conditional heteroscedsticity (EGARCH) models. They argued that the improvements made by leveraging in EGARCH and GJR-GARCH models did not improve forecasting accuracy.

Meanwhile, Brooks and Burke (1998) used modified information criteria to select models from the GARCH family. Using weekly exchange rate returns for the Canadian dollar, German mark, and Japanese yen against the US dollar for the period from March 1973 to September 1989, they compared the performance of different out-ofsample models. They found that the out-of-sample forecasting accuracy of the models compared favorably on mean absolute errors but less favorably on mean squared errors with those generated by commonly used $\operatorname{GARCH}(1,1)$ models. However, Hansen and Lunde (2005) did an out-of-sample comparison of 330 different GARCH family models using two types of assets: daily exchange rates (Deutsche Mark (DM)-US dollar) and IBM stock prices. They found that different models were the best for forecasting the volatility of the two types of assets. In terms of forecasting accuracy, $\operatorname{GARCH}(1,1)$ outperformed the other models. For IBM stock prices, however, the models with leverage effects performed better than $\operatorname{GARCH}(1,1)$.

Herwartz and Reimers (2002) analyzed daily exchange rate changes between the Deutsche mark (DM) and the US dollar and the DM and the Japanese yen (JPY) for the period from 1975 to 1998 . They used a $\operatorname{GARCH}(1,1)$ model with leptokurtic innovations to capture volatility clustering, and they found that the identified points of structural change were subject to changes in monetary policies in the US and Japan. Similarly, Çağlayan, Ün, and Dayığlu (2013) modeled the exchange rate volatility of MIST (Mexico, Indonesia, South Korea, and Turkey) countries against the US dollar using asymmetric GARCH models. They used monthly exchange rate data for the period from 1993 to 2013 to investigate leverage effects and fat-tailed features. They identified the existence of asymmetrical and leveraging effects in the exchange rates of MIST countries against the US dollar. Vee, Gonpot, and Sookia (2011) also examined the forecasting accuracy of $\operatorname{GARCH}(1,1)$ using Student's $t$ and generalized error distribution (GED). Using daily data for exchange rates between the US dollar and the Mauritian rupee, they compared the mean absolute error (MAE) and root mean squared error (RMSE) of the models based on forecasting estimates. They found that $\operatorname{GARCH}(1,1)$ with GED had better forecasting accuracy compared to that using Student's $t$-distribution.

In contrast, Tse (1998) examined the conditional heteroscedasticity of yen-US dollar exchange rates using daily observations for the period from 1978 to 1994. Extending 
APARCH models to a process that was fractionally integrated; they found that, unlike the stock market, the appreciation and depreciation shock of the yen against the US dollar affected future volatility in a similar fashion. They argued that there is no substantial difference between fractionally integrated models and stable models. More recently, Pelinescu (2014) analyzed exchange rates between the Romanian leu and the euro considering the influence of other macroeconomic variables. Using daily observations for the period from 2000 to 2013, the study found that the exchange rates consisted of ARCH processes, and exchange returns were correlated with volatility.

To the best of our knowledge, relatively few studies have aimed to model BDT-US dollar exchange rates. In one recent example, Alam and Rahman (2012) modeled the aforementioned exchange rates using daily data for the period from July 2006 to April 2012. That study has limitations since excess skewness and kurtosis issues were detected but not addressed. Further, the lag specification of the mean equation was not properly addressed. Such serious flaws can result in misleading conclusions. Therefore, finding a proper model with an appropriate assumption for the distribution of errors would be a valuable contribution to the field of exchange rate modeling in Bangladesh regarding the BDT against the US dollar.

\section{Methods}

\section{Data and variable construction}

The data used for this study covered January 1, 2008 to April 30, 2015. These were daily observations of the nominal exchange rate of the Bangladeshi taka (BDT) against the US dollar supplied by Bangladesh Bank, the country's central bank. Since the nominal exchange rate series is usually nonstationary, and hence is not appropriate for analysis, we converted the series into the rate of return on exchange rate by following logarithmic transformation. In particular, we used the following formula to calculate the rate of return on exchange rate:

$$
\begin{aligned}
r_{t} & =\ln \left(\frac{f x_{t}}{f x_{t-1}}\right) \\
\text { or, } \quad r_{t} & =\ln \left(f x_{t}\right)-\ln \left(f x_{t-1}\right)
\end{aligned}
$$

Here, $r_{t}$ stands for exchange rate return at period $\mathrm{t} f x_{t}$ and $f x_{t-1}$ stand for the nominal exchange rate of the BDT-US dollar at period $t$ and $(t-1)$. The statistical software EViews 9 (Econometric Views Version 9, IHS Markit Ltd.) was used to perform the quantitative exercise.

\section{Specification of different models}

It is well established that when modeling volatility using GARCH family models, the appropriate specification of the mean equation is vitally important. The misspecification of that equation could fail to address the autocorrelation problem that could arise in the volatility model. Therefore, we estimated all of the GARCH family models using three different specifications for the mean equations. The first is with a constant only, the second is with a constant and one autoregressive variable (i.e., $\mathrm{AR}(1)$ ), and the third is constant and has two autoregressive variables (i.e., $\mathrm{AR}(2)$ ). They can be expressed as follows: 


$$
\begin{aligned}
& \text { Mean Equations : } r_{t}=\mu+\varepsilon_{t} \\
& r_{t}=\mu+\rho_{1} r_{t-1}+\varepsilon_{t} \\
& r_{t}=\mu+\rho_{1} r_{t-1}+\rho_{2} r_{t-2}+\varepsilon_{t}
\end{aligned}
$$

To specify the variance equation to model volatility presence in differenced logarithmic exchange rates (i.e., exchange rate returns), we used five different GARCH family models, each of which has a different purpose. In particular, we modeled the variance for the above three mean equations using GARCH, APARCH, EGARCH, TGARCH, and IGARCH models. The sensitivity of the estimation results of the models was checked by changing the distribution assumptions. More specifically, the sensitivity and appropriateness of the estimation results were observed by changing the distribution assumption from normal to Student's $t$-distribution. The reason for this is that in the literature on financial asset returns, it is established that the return variable is more likely to follow a "levy distribution" with "fat tails," and kurtosis is likely to increase with data frequency (Alexander, 1961; Andersen \& Bollerslev, 1998).

Engle (1982) pioneered modeling volatility using conditionally heteroscedastic regression with the autoregressive conditional heteroscedasticity (ARCH) model. One major problem with such modeling is that the required lag length usually remains large, which means it needs to estimate a large number of parameters to predict volatility. In contrast, the generalized autoregressive conditional heteroscedasticity (GARCH) models proposed by Bollerslev (1986) allow conditional variance to depend upon its own lag. This typically reduces the number of required ARCH lags when predicting volatility.

Nevertheless, we assumed the following general form for the variance equation:

$$
\text { Variance Equation }: \varepsilon_{t}=\sqrt{h_{t}} v_{t}, \text { where } v_{t} \sim \operatorname{iid}(0,1)
$$

Depending on the specification of $h_{t}$ in Eq. (4), we can have several possible models within the GARCH family. In particular, we estimated the following specification of GARCH family models for estimating volatility in logarithmic exchange rates:

$$
\begin{aligned}
& \operatorname{GARCH}(1,1): h_{t}=\eta+\alpha \varepsilon_{t-1}^{2}+\beta h_{t-1} \\
& \operatorname{APARCH}(1,1): h_{t}^{\delta}=\eta+\alpha\left(\left|\varepsilon_{t-1}\right|-\gamma \varepsilon_{t-1}\right)^{\delta}+\beta h_{t-1}^{\delta} \\
& \operatorname{EGARCH}(1,1): \ln h_{t}=\eta+\alpha\left|\frac{\varepsilon_{t-1}}{\sqrt{h}_{t-1}}\right|+\gamma\left(\frac{\varepsilon_{t-1}}{\sqrt{h_{t-1}}}\right)+\beta \ln h_{t-1} \\
& \operatorname{TGARCH}(1,1): h_{t}=\eta+\alpha \varepsilon_{t-1}^{2}+\lambda d_{t-1} \varepsilon_{t-1}^{2}+\beta h_{t-1}, \quad d_{t-1}=\left\{\begin{array}{l}
1, \text { if } \varepsilon_{t-1}<0 \\
0, \text { if } \varepsilon_{t-1} \geq 0
\end{array}\right. \\
& \operatorname{IGARCH}(1,1): h_{t}=\alpha \varepsilon_{t-1}^{2}+(1-\alpha) h_{t-1}
\end{aligned}
$$

Here, the $\operatorname{GARCH}(1,1)$ model consists of one $\mathrm{ARCH}$ term denoted as $\varepsilon_{t-1}^{2}$ and one GARCH term denoted as $h_{t-1}$. For the variance to remain well behaved, some restrictions needed to be imposed: $\eta>0, \alpha \geq 0$, and $\beta \geq 0$. The sum of the ARCH coefficient and GARCH coefficient governs the persistency of volatility shocks. Their sum should be less than the unit $(\alpha+\beta<1)$ to ensure that series $\varepsilon_{t}$ is stationary and the variance is positive. 
To allow for possible nonlinearities in the parameters of the variance equation, Ding, Granger and Engel (1993) developed the asymmetric power autoregressive conditional heteroscedasticity (APARCH) model. In the above APARCH model, $\delta$ denotes the power parameter that requires the condition $\delta>0$, and $\gamma$ is the parameter capturing asymmetry or leverage effect, which requires the condition $|\gamma| \leq 1$.

The standard $\operatorname{GARCH}(1,1)$ model suggests that the shock in $\varepsilon_{t-1}$ has the same effect regardless of whether $\varepsilon_{t-1}>0$ or $\varepsilon_{t-1}<0$. Nevertheless, a typical feature of financial data is that negative shocks generate more volatility compared to positive shocks. Aiming to incorporate this asymmetrical effect in financial data, Nelson (1991) proposed the exponential generalized autoregressive conditional heteroscedasticity (EGARCH) model. In the EGARCH specification, $\gamma$ is the asymmetry parameter measuring leverage effect, $\alpha$ is the size parameter measuring the magnitude of shocks, and persistency is captured through $\beta$. An important feature of the EGARCH specification is that conditional variance is an exponential function, thus there is no need for nonnegetivity restrictions, as in earlier GARCH specifications.

Introduced by Zakoian (1994) and Glosten, Jagannathan, and Runkle (1993), threshold generalized autoregressive conditional heteroscedasticity (TGARCH) is another model developed to analyze leverage affects. In the above $\operatorname{TGARCH}(1,1)$ model, $\varepsilon_{t-1}>0$ (good news) and $\varepsilon_{t-1}<0$ (bad news) produce a differential effect on volatility. Here, good news has an impact of $\alpha$ while bad news has an impact of $(\alpha+\gamma)$. Thus, when $\gamma>0$, the increase in volatility due to bad news is greater than that for good news, and we can conclude that there is a leverage effect. Similar to standard GARCH models, we also need nonnegative restrictions here for $\alpha, \gamma$, and $\beta$.

A nonstationary GARCH model (i.e., GARCH model with unit roots) can be regarded as an integrated generalized autoregressive conditional heteroscedasticity (IGARCH) model. This model was originally developed by Engle and Bollerslev (1986). In practice, when the parameters of the GARCH model are restricted to a sum equal to one and ignore the constant term, a standard GARCH model is transformed into an IGARCH model. In the above IGARCH model, the additional constraints are $\{\alpha+(1-\alpha)\}=1$ and $0<\alpha<1$.

\section{Estimation Results and Discussion}

Table 1 shows the estimation results of the different conditional mean models for the differenced logarithmic exchange rate using Ordinary Least Squares (OLS) method. OLS was applied to estimate regression since the series was observed to be mean reverting (Table 9 in Appendix). In particular, three different conditional mean equations were estimated: one with the constant only, one with the $A R(1)$ term, and one with $A R(2)$ terms. The models were not augmented with further AR terms since they were not significant (Fig. 1 in Appendix). As the results show, in Model 1, the constant term is significant, and the F-statistic, testing the null of the absence of the $\mathrm{ARCH}$ effect in the differenced logarithmic exchange rate, is statistically significant at the $1 \%$ level. In Model 2, the conditional mean model was augmented with the AR(1) term, which was found to be statistically significant along with the test for heteroscedastic ARCH effects. The conditional mean model was augmented further with AR(2) terms in Model 3. The estimation results reveal that both $A R(1)$ and $A R(2)$ terms are 
Table 1 Estimation of different conditional mean models and testing for ARCH effect

\begin{tabular}{llll}
\hline Variables & Coefficients & & $(3)$ \\
\cline { 2 - 4 } & $(1)$ & $(2)$ & 0.00200 \\
\hline Dependent Variable, $r_{t}$ & $0.007039^{*}$ & $0.002324^{* * *}$ & $(0.001315)$ \\
$\mu$ & $(0.001770)$ & $(0.001325)$ & $0.577656^{*}$ \\
$r_{t-1}$ & & $0.670082^{*}$ & $(0.023430)$ \\
& & $(0.017550)$ & $0.137930^{*}$ \\
$r_{t-2}$ & & $(0.023430)$ \\
& & & $0.001852^{*}$ \\
ARCH Effect (Dependent Variable, $\left.\varepsilon_{t}^{2}\right)$ & $0.001964^{*}$ & $(0.000419)$ \\
Constant & $0.001824^{* *}$ & $(0.000417)$ & $0.394310^{*}$ \\
& $(0.000779)$ & $0.369592^{*}$ & $(0.021739)$ \\
$\varepsilon_{t-1}^{2}$ & $0.677218^{*}$ & $(0.021975)$ & \\
HO: No ARCH Effect & $(0.017396)$ & & $328.9958^{*}$ \\
F- Statistic & & $282.8792^{*}$ & 0.000000 \\
Probability & $1515.543^{*}$ & 0.000000 & \\
\hline
\end{tabular}

Standard Errors are in Parenthesis. ${ }^{* *}$ indicates significant at $10 \%$ level, ${ }^{* *}$ significant at $5 \%$ level and ${ }^{*}$ indicates that at $1 \%$ level

significant along with the F-statistic for the heteroscedastic ARCH effect. Thus, it is established that the differenced logarithmic exchange rate of the taka against the US dollar is conditionally heteroscedastic, and this remains crucially important for modeling volatility clustering. The existence of volatility clustering in the taka-US dollar exchange rate is also evident in the residual plot in Fig. 2 (Appendix).

Since the ARCH effect was detected in the model, GARCH estimation was performed with different specifications. In particular, the $\operatorname{GARCH}(1,1)$ and $\operatorname{APARCH}(1,1)$ models were initially estimated with normal error distribution assumption. While the GARCH model was applied for the purpose of capturing variance dynamics, the APARCH model was applied to test for the presence of asymmetric volatility effects in the variance dynamics of exchange rate returns.

Table 2 shows the estimation results. Here, it is evident that the autoregressive coefficients of the lagged dependent variables for mean equations $\rho_{1}$ and $\rho_{2}$ are statistically significant. In all of the specifications, the coefficients of the GARCH components (i.e., $\alpha$ and $\beta$ ) are positive and statistically significant at the $1 \%$ level. However, as their sum exceeds 1 , the residuals of the regressions would be nonstationary, and hence variance would be indefinite. Since the residual of the GARCH model should be white noise, a diagnostic test was performed in the form of the Ljung-Box Q-test under the null hypothesis $\left(\mathrm{H}_{0}\right.$ : No Serial Correlation in the Error Term). We calculated Q-statistics for the standardized residuals (Q1) and for their squared values (Q2) (especially testing for the fourth and eighth lag, inspired by Tse (1998)). All of the Q1-statistics were significant at the 5\% level. Thus, there was not enough evidence to reject the null hypothesis of no serial correlation in the error term. Also, the F-statistic confirmed that the models still had ARCH effects.

From the APARCH specification in Table 2, it is evident that the autoregressive coefficients of the lagged dependent variables for mean equations $\rho_{1}$ and $\rho_{2}$ are 
Table 2 Estimation results of GARCH and APARCH models with normal distribution

\begin{tabular}{|c|c|c|c|c|c|c|}
\hline \multirow[t]{2}{*}{ Coefficients } & \multicolumn{3}{|l|}{ GARCH } & \multicolumn{3}{|l|}{ APARCH } \\
\hline & (1) & (2) & (3) & $(4)$ & (5) & (6) \\
\hline \multirow[t]{2}{*}{$\mu$} & -0.000226 & -0.000221 & $-0.000187^{* *}$ & $-3.93 \mathrm{E}-06$ & 0.000107 & 0.000226 \\
\hline & $(0.000286)$ & $(0.000294)$ & $(0.000277)$ & $(0.000219)$ & $(0.000231)$ & $(0.000235)$ \\
\hline \multirow[t]{2}{*}{$\rho_{1}$} & & $0.193417^{*}$ & $0.140156^{* *}$ & & $0.224911^{*}$ & $0.176892^{*}$ \\
\hline & & $(0.054895)$ & $(0.058168)$ & & $(0.045801)$ & $(0.047702)$ \\
\hline \multirow[t]{2}{*}{$\rho_{2}$} & & & $0.219073^{*}$ & & & $0.191613^{*}$ \\
\hline & & & $(0.069243)$ & & & $(0.054318)$ \\
\hline \multirow[t]{2}{*}{$\eta$} & $2.33 \mathrm{E}-06^{* * *}$ & $2.37 \mathrm{E}-06^{* * *}$ & $2.52 \mathrm{E}-06^{* * *}$ & $2.52 \mathrm{E}-05$ & $3.22 \mathrm{E}-05$ & $2.48 \mathrm{E}-05$ \\
\hline & $(1.22 \mathrm{E}-06)$ & $(1.31 E-06)$ & (1.36E-06) & $(3.80 \mathrm{E}-05)$ & $(4.72 \mathrm{E}-05)$ & (3.97E-05) \\
\hline \multirow[t]{2}{*}{ a } & $0.180840^{*}$ & $0.182424^{*}$ & $0.208203^{*}$ & $0.175477^{*}$ & $0.167971^{*}$ & $0.180086^{*}$ \\
\hline & $(0.033305)$ & $(0.035090)$ & $(0.044322)$ & $(0.032685)$ & $(0.032557)$ & $(0.038836)$ \\
\hline \multirow[t]{2}{*}{ Y } & & & & $-0.289609^{*}$ & $-0.332848^{*}$ & $-0.34263^{* *}$ \\
\hline & & & & $(0.084911)$ & $(0.113350)$ & $(0.140916)$ \\
\hline \multirow[t]{2}{*}{$\delta$} & & & & $1.533712^{*}$ & $1.485285^{*}$ & $1.541664^{*}$ \\
\hline & & & & $(0.270681)$ & $(0.266742)$ & $(0.294524)$ \\
\hline \multirow[t]{2}{*}{$\beta$} & $0.873895^{*}$ & $0.875357^{*}$ & $0.865345^{*}$ & $0.885786^{*}$ & $0.889983^{*}$ & $0.882629^{*}$ \\
\hline & (0.019489) & $(0.019747)$ & $(0.021975)$ & $(0.020222)$ & $(0.020219)$ & $(0.022510)$ \\
\hline Q1(4) & $172.59^{*}$ & $79.968^{*}$ & $35.571^{*}$ & $161.98^{*}$ & $59.366^{*}$ & $28.906^{*}$ \\
\hline Q1(8) & $241.95^{*}$ & $124.84^{*}$ & $60.316^{*}$ & $224.18^{*}$ & $96.379^{*}$ & $50.349^{*}$ \\
\hline Q2(4) & 6.3326 & 4.982 & 3.8738 & $19.204^{*}$ & $20.390^{*}$ & $19.377^{*}$ \\
\hline Q2(8) & 7.3836 & 6.1325 & 4.8640 & $20.747^{*}$ & $22.297^{*}$ & $21.219^{*}$ \\
\hline Log Likelihood & 4052.775 & 4065.950 & 4087.309 & 4104.165 & 4127.830 & 4152.042 \\
\hline F Stat. & $5.6784^{* *}$ & $4.1581^{* *}$ & $3.029272^{* * *}$ & $17.0974^{*}$ & $15.8075^{*}$ & $14.90734^{*}$ \\
\hline Prob. & 0.0173 & 0.0416 & 0.0819 & 0.0000 & 0.0001 & 0.0001 \\
\hline
\end{tabular}

Robust Standard Errors are in Parenthesis. *** indicates significant at $10 \%$ level, ** indicates significant at $5 \%$ level and * indicates that at $1 \%$ level

statistically significant. The coefficients $\alpha$ and $\beta$ were again found to be positive and statistically significant, having a sum exceeding 1 for all of the specifications. The coefficient $\delta$ is positive and significant, and not equal to 2, establishing that it is not a standard GARCH model (Ding, Granger, \& Engle 1993). The significance and sign of the coefficient $\gamma$ determine the leverage effect.

The positive significant value of $\gamma$ indicates the existence of a leverage effect where negative past values of $\varepsilon_{t}$ increase volatility more than positive past values of the same magnitude. Meanwhile, the negative significant value of $\gamma$ indicates the existence of a leverage effect in the opposite direction: positive past values of $\varepsilon_{t}$ increase volatility more than negative past values of the same magnitude. As the table shows, the leverage coefficient is negative and significant. Thus, an asymmetric volatility effect exists for exchange rate returns. More specifically, the appreciation and depreciation of the taka against the US dollar does not necessarily cause symmetric variation in the exchange rate return. However, the test results for detecting serial correlation establish that all of the specifications have a serial correlation problem, and the $F$-statistic shows that an ARCH effect still exists. Figure 3 (Appendix) shows that none of the above models have normally distributed errors on the basis of the Jarque-Bera test statistic. 
Since it was established that the distribution of error terms in different models was not normal, we checked the estimation results using the assumption of Student's $t$-distribution for the error terms. To justify this, we also checked the skewness and kurtosis of the exchange rate return series. Table 10 (Appendix) shows that the exchange rate return is highly skewed. The distribution is also leptokurtic, implying that its central peak is higher and sharper with longer and fatter tails. This finding is in line with Mandelbrot (1963), who found fat-tailed and excess kurtosis for the rate of return, which has been further clarified for different financial assets in other studies. Thus, following Bollerslev (1987); Vee, Gonpot, and Sookia (2011); and Çağlayan, Ün, and Dayığlu (2013), we examined the estimation results using Student's $t$-distribution for the error terms. Table 3 shows the results. The autoregressive coefficients in both GARCH and APARCH specifications were found significant, as before. Here, the ARCH parameter denoted by $\beta$ measures the reaction of conditional volatility to market shocks (i.e., it measures the variance response in exchange rate returns against appreciation or depreciation). On the other hand, the GARCH parameter denoted by $\beta$ measures the persistence of conditional volatility, regardless of shocks to the market. Both coefficients were found to be positive and significant, implying that variance in exchange rate returns

Table 3 Estimation results of GARCH and APARCH models with Student's $t$-distribution

\begin{tabular}{|c|c|c|c|c|c|c|}
\hline \multirow[t]{2}{*}{ Coefficients } & \multicolumn{3}{|l|}{ GARCH } & \multicolumn{3}{|l|}{ APARCH } \\
\hline & (1) & (2) & (3) & (4) & (5) & (6) \\
\hline \multirow[t]{2}{*}{$\bar{\mu}$} & $1.79 \mathrm{E}-07$ & $6.72 \mathrm{E}-08$ & $-4.08 \mathrm{E}-08$ & $7.92 \mathrm{E}-10$ & $4.36 \mathrm{E}-09$ & $2.25 \mathrm{E}-09$ \\
\hline & $(1.37 \mathrm{E}-07)$ & $(1.42 \mathrm{E}-07)$ & $(1.56 \mathrm{E}-07)$ & $(1.84 \mathrm{E}-07)$ & $(1.03 \mathrm{E}-07)$ & (6.09E-08) \\
\hline \multirow[t]{2}{*}{$\rho_{1}$} & & $0.227924^{*}$ & $0.246680^{*}$ & & $0.149727^{*}$ & $0.095646^{*}$ \\
\hline & & $(0.022967)$ & $(0.018652)$ & & $(0.016292)$ & $(0.011675)$ \\
\hline \multirow[t]{2}{*}{$\rho_{2}$} & & & $0.166564^{*}$ & & & $0.073848^{*}$ \\
\hline & & & $(0.016849)$ & & & $(0.009821)$ \\
\hline \multirow[t]{2}{*}{$\eta$} & $2.76 \mathrm{E}-13$ & $2.01 \mathrm{E}-13$ & $1.78 \mathrm{E}-13$ & 0.000808 & $2.70 \mathrm{E}-05$ & 0.000190 \\
\hline & $(2.08 \mathrm{E}-13)$ & $(1.50 \mathrm{E}-13)$ & $(1.12 \mathrm{E}-13)$ & $(0.000809)$ & (6.55E-05) & $(0.000549)$ \\
\hline \multirow[t]{2}{*}{ a } & $0.926099^{*}$ & $1.889860^{*}$ & $1.633760^{*}$ & $1.421359^{* *}$ & $1.707541^{*}$ & $1.445461^{*}$ \\
\hline & $(0.073253)$ & $(0.426702)$ & $(0.452555)$ & $(0.669212)$ & $(0.501460)$ & $(0.506596)$ \\
\hline \multirow[t]{2}{*}{ Y } & & & & $-0.068862^{* *}$ & $-0.078959^{* * *}$ & $-0.106666^{* *}$ \\
\hline & & & & (0.032925) & $(0.041074)$ & $(0.044544)$ \\
\hline \multirow[t]{2}{*}{$\delta$} & & & & $0.611742^{*}$ & $0.671478^{*}$ & $0.530577^{*}$ \\
\hline & & & & $(0.021520)$ & $(0.028684)$ & $(0.019776)$ \\
\hline \multirow[t]{2}{*}{$\beta$} & $0.464984^{*}$ & $0.514459^{*}$ & $0.503470^{*}$ & $0.653877^{*}$ & $0.574994^{*}$ & $0.593071^{*}$ \\
\hline & $(0.004546)$ & $(0.004297)$ & $(0.004305)$ & $(0.008688)$ & $(0.012415)$ & $(0.009463)$ \\
\hline Q1(4) & 0.0032 & 0.0015 & 0.0015 & 0.0002 & 0.00002 & 0.000004 \\
\hline Q1(8) & 0.0064 & 0.0029 & 0.0030 & 0.0231 & 0.00003 & 0.00001 \\
\hline Q2(4) & 0.0321 & 0.0268 & 0.0270 & 0.0802 & 0.0569 & 0.0551 \\
\hline Q2(8) & 0.0644 & 0.0538 & 0.0542 & 0.1603 & 0.1142 & 0.1105 \\
\hline Log Likelihood & 6606.627 & 6622.211 & 6690.907 & 6717.160 & 7694.906 & 7809.244 \\
\hline F Statistic & 0.007976 & 0.00666 & 0.006713 & 0.01994 & 0.01414 & 0.013687 \\
\hline Probability & 0.9288 & 0.9349 & 0.9347 & 0.8877 & 0.9053 & 0.9069 \\
\hline
\end{tabular}

Robust Standard Errors are in Parenthesis. ${ }^{* * *}$ indicates significant at $10 \%$ level, ${ }^{* *}$ indicates significant at $5 \%$ level and *indicates that at $1 \%$ level 
for the taka against the US dollar is responsive and persistent against shocks defined as appreciation or depreciation. However, in all of the models, since their sum exceeds a value of 1 , the variance is arguably infinite and nonstationary. The existence of an asymmetric volatility effect is again established in the APARCH model.

Nonetheless, the diagnostic indicators reveal that there is no ARCH effect in either the GARCH and APARCH specifications; also, all models successfully passed the noautocorrelation test in residuals. Therefore, it is more appropriate to perform further analysis using Student's $t$-distribution. It is worth noting that in all of the types of models, regardless of different distribution assumptions for the residuals, the coefficients for the ARCH and GARCH components sum to more than 1. Also, the constant terms in the variance equations of the GARCH and APARCH models using Student's $t$-distribution were not significantly different from 0 . Thus, as the necessary nonnegativity restrictions have not been satisfied, the variance is not well behaved.

Thus, to incorporate the asymmetric volatility effect and eliminate the problem of nonnegativity restrictions, we estimated an EGARCH model. Table 4 shows the estimation results of the EGARCH model with different specifications for the mean equations, using both normal and Student's $t$-distribution for the residual. The autoregressive coefficients were significant when we estimated EGARCH using normally distributed errors. Here, in the variance equation, $\gamma$ represents what is

Table 4 Estimation results for EGARCH model

\begin{tabular}{|c|c|c|c|c|c|c|}
\hline \multirow[t]{2}{*}{ Variables } & \multicolumn{3}{|c|}{ EGARCH with normal distribution } & \multicolumn{3}{|c|}{ EGARCH with $t$-distribution } \\
\hline & $(1)$ & (2) & (3) & $(4)$ & (5) & (6) \\
\hline \multirow[t]{2}{*}{$\mu$} & $2.04 \mathrm{E}-08$ & $3.27 E-09$ & $-3.66 \mathrm{E}-08$ & $4.29 \mathrm{E}-08$ & $2.57 \mathrm{E}-08$ & $-1.85 \mathrm{E}-08$ \\
\hline & $(1.17 \mathrm{E}-06)$ & $(1.43 \mathrm{E}-06)$ & $(4.97 \mathrm{E}-07)$ & $(1.93 \mathrm{E}-06)$ & $(1.61 E-06)$ & $(1.64 \mathrm{E}-06)$ \\
\hline \multirow[t]{2}{*}{$\rho_{1}$} & & $0.263417^{*}$ & $0.350785^{* *}$ & & $0.161735^{*}$ & $0.146973^{*}$ \\
\hline & & $(0.051723)$ & $(0.153884)$ & & $(0.015344)$ & $(0.014631)$ \\
\hline \multirow[t]{2}{*}{$\rho_{2}$} & & & $0.350488^{*}$ & & & $0.119350^{*}$ \\
\hline & & & $(0.125083)$ & & & $(0.013932)$ \\
\hline \multirow[t]{2}{*}{$\eta$} & $-0.565951^{*}$ & $-0.678004^{*}$ & $-0.605468^{*}$ & $-0.636386^{*}$ & $-0.696469 *$ & $-0.758190^{*}$ \\
\hline & $(0.065684)$ & $(0.066833)$ & $(0.065839)$ & $(0.210477)$ & $(0.226475)$ & $(0.151225)$ \\
\hline \multirow[t]{2}{*}{$a$} & $0.322317^{*}$ & $0.381764^{*}$ & $0.342639^{*}$ & 1.743955 & 2.628468 & 2.047842 \\
\hline & $(0.045776)$ & $(0.050371)$ & $(0.078282)$ & $(3.064486)$ & (4.199223) & $(2.094103)$ \\
\hline \multirow[t]{2}{*}{$\gamma$} & 0.057201 & 0.066029 & -0.031695 & 0.167936 & 0.409331 & 0.302450 \\
\hline & $(0.037783)$ & $(0.054214)$ & $(0.221024)$ & $(0.295404)$ & (0.651932) & $(0.311216)$ \\
\hline \multirow[t]{2}{*}{$\beta$} & $0.945939 *$ & $0.934308^{*}$ & $0.942450^{*}$ & $0.941501^{*}$ & $0.931442^{*}$ & $0.929085^{*}$ \\
\hline & $(0.006794)$ & $(0.006133)$ & $(0.007135)$ & $(0.001939)$ & $(0.002482)$ & $(0.002585)$ \\
\hline Q1(4) & $293.54^{*}$ & $102.11^{*}$ & $14.129^{*}$ & $44.070^{*}$ & $26.663^{*}$ & $17.440^{*}$ \\
\hline Q1(8) & $397.12^{*}$ & $160.61^{*}$ & $19.778^{* *}$ & $65.108^{*}$ & $42.640^{*}$ & $29.617^{*}$ \\
\hline Q2(4) & $15.604^{*}$ & 3.4865 & 1.1215 & 0.3888 & 0.7209 & 0.7762 \\
\hline Q2(8) & $397.12^{*}$ & 6.3806 & 2.2757 & 0.7328 & 1.3139 & 1.4064 \\
\hline Log Likelihood & 4159.549 & 4155.077 & 4087.921 & 5186.759 & 5205.489 & 5213.334 \\
\hline F Statistic & $13.99454^{*}$ & $2.877947^{* * *}$ & 0.888492 & 0.081133 & 0.167294 & 0.180243 \\
\hline Probability & 0.0002 & 0.0900 & 0.3460 & 0.7758 & 0.6826 & 0.6712 \\
\hline
\end{tabular}

Robust Standard Errors are in Parenthesis. *** indicates significant at $10 \%$ level, ${ }^{* *}$ indicates significant at $5 \%$ level and * indicates that at $1 \%$ level 
popularly known as the "asymmetry parameter," and $\alpha$ represents the "size parameter." The former measures the asymmetric effect on volatility while the latter measures the effect of the magnitude of shocks about their mean. It can be observed that though the size parameter is significant, the asymmetric parameter is insignificant, establishing the possible absence of an asymmetric effect on volatility.

A look at the diagnostic indicators reveals that the model still contains an $\mathrm{ARCH}$ effect and has a serial correlation problem. Furthermore, when the model is reestimated using Student's $t$-distribution for residuals, both the asymmetry and size parameters become statistically insignificant. Therefore, according to the EGARCH specification, the taka-US dollar exchange rate return exhibits symmetric volatility; appreciation and depreciation could possibly have a similar effect on future volatility. This is in line with Diebold and Nerlove (1989); Bollerslev, Chou, and Kroner (1992); and Tse (1998) since the diagnostic indicators showed no ARCH effect, and the model overcame the autocorrelation problem based on the Ljung-Box Q-test using squared residuals. However, the autocorrelation problem remained when regular residuals were used for the test.

Since EGARCH disregarded the possible existence of an asymmetric volatility effect, we tried another parameterization-namely, TGARCH. Table 5 shows the estimation results. All of the nonnegativity restrictions required for model validity were satisfied. Also, the parameter $\lambda$, which captures the asymmetric response of volatility to shocks,

Table 5 Estimation results for TGARCH model

\begin{tabular}{|c|c|c|c|}
\hline \multirow[t]{2}{*}{ Variables } & \multicolumn{3}{|c|}{ TGARCH (Normal distribution) } \\
\hline & (1) & (2) & (3) \\
\hline \multirow[t]{2}{*}{$\mu$} & $-3.67 \mathrm{E}-05$ & 4.94E-05 & 0.000154 \\
\hline & $(0.000235)$ & $(0.000254)$ & $(0.000234)$ \\
\hline \multirow[t]{2}{*}{$\rho_{1}$} & & $0.222718^{*}$ & $0.169813^{*}$ \\
\hline & & $(0.045755)$ & $(0.020729)$ \\
\hline \multirow[t]{2}{*}{$\rho_{2}$} & & & $0.214483^{*}$ \\
\hline & & & $(0.020328)$ \\
\hline \multirow[t]{2}{*}{$\eta$} & $2.39 \mathrm{E}-06^{* *}$ & $2.41 \mathrm{E}-06^{* * *}$ & $2.46 \mathrm{E}-06^{*}$ \\
\hline & $(1.21 \mathrm{E}-06)$ & $(1.28 \mathrm{E}-06)$ & (7.95E-08) \\
\hline \multirow[t]{2}{*}{ a } & $0.293310^{*}$ & $0.303622^{*}$ & $0.341319^{*}$ \\
\hline & $(0.042445)$ & $(0.048643)$ & $(0.014608)$ \\
\hline \multirow[t]{2}{*}{ y } & $-0.194578^{*}$ & $-0.215880^{*}$ & $-0.254191^{*}$ \\
\hline & $(0.039799)$ & $(0.047940)$ & $(0.016232)$ \\
\hline \multirow[t]{2}{*}{$\beta$} & $0.864521^{*}$ & $0.866679^{*}$ & $0.859486^{*}$ \\
\hline & $(0.020969)$ & $(0.021193)$ & $(0.002350)$ \\
\hline Q1(4) & $164.03^{*}$ & $63.817^{*}$ & $29.131^{*}$ \\
\hline Q1(8) & $230.46^{*}$ & $102.16^{*}$ & $48.891^{*}$ \\
\hline Q2(4) & $8.8747^{* * *}$ & $8.6272^{* * *}$ & $10.023^{*}$ \\
\hline Q2(8) & 10.346 & 10.343 & 11.764 \\
\hline Log Likelihood & 4096.761 & 4118.817 & 4145.995 \\
\hline F Statistic & $7.942155^{*}$ & $6.577262^{* * *}$ & $7.433103^{*}$ \\
\hline Probability & 0.0049 & 0.0104 & 0.0065 \\
\hline
\end{tabular}

Robust Standard Errors are in Parenthesis. *** indicates significant at 10\% level, ** indicates significant at 5\% level and * indicates that at $1 \%$ level 
was found to be negative and consistently significant for all of the models, indicating the possible existence of an asymmetric volatility effect. However, the findings should be regarded with caution since this estimation is valid only under normal error distribution. ${ }^{3}$ Furthermore, this model also shows an autocorrelation problem, and there is still an ARCH effect.

Finally, since it has been observed that the sum of the persistence parameters exceeds the unitary value in earlier GARCH estimations, it can be deduced that the variance might not be well behaved in such models. Therefore, it would be interesting to model volatility clustering with such models while imposing restrictions on the persistence parameters. One popular restriction on the persistence parameters of GARCH models is referred to as "persistence parameters sum up to unit." The estimation of GARCH models with this restriction leads to IGARCH specifications. Table 6 shows IGARCH estimation with normally distributed errors as well as errors following Student's $t$-distribution.

It can be observed from the estimation results of the IGARCH models that the restriction that was applied is valid. Moreover, the IGARCH specifications successfully overcame all of the diagnostic tests when Student's $t$-distribution, rather than normal distribution, was used as the error distribution. There was no $\mathrm{ARCH}$ effect and no autocorrelation detected in the regular and squared residuals

Finally, the evidence indicates that all of the models $(\mathrm{GARCH}, \mathrm{APARCH}, \mathrm{EGARCH}$, and IGARCH) satisfy the required diagnostic standard under Student's $t$-distribution as the assumption for residuals. Further, the log-likelihood for all of the models was improved when the aforementioned distribution was used.

Table 6 Estimation results for IGARCH model

\begin{tabular}{|c|c|c|c|c|c|c|}
\hline \multirow[t]{2}{*}{ Variables } & \multicolumn{3}{|c|}{ IGARCH with normal distribution } & \multicolumn{3}{|c|}{ IGARCH with $t$-distribution } \\
\hline & (1) & (2) & (3) & (4) & (5) & (6) \\
\hline \multirow[t]{2}{*}{$\mu$} & $0.002930^{*}$ & $0.002884^{*}$ & $0.002865^{*}$ & $7.55 \mathrm{E}-07^{*}$ & $1.53 \mathrm{E}-09$ & $-1.19 \mathrm{E}-07$ \\
\hline & $(0.000839)$ & $(0.000920)$ & $(0.000928)$ & (8.18E-08) & (9.17E-06) & $(1.01 \mathrm{E}-07)$ \\
\hline \multirow[t]{2}{*}{$\rho_{1}$} & & $0.205516^{*}$ & $0.173207^{*}$ & & $0.265356^{*}$ & $0.243118^{*}$ \\
\hline & & $(0.056778)$ & $(0.060553)$ & & $(0.011288)$ & $(0.011705)$ \\
\hline \multirow[t]{2}{*}{$\rho_{2}$} & & & $0.170491^{*}$ & & & $0.161135^{*}$ \\
\hline & & & $(0.059969)$ & & & $(0.011974)$ \\
\hline \multirow[t]{2}{*}{$a$} & $0.081458^{*}$ & $0.075343^{*}$ & $0.073077^{*}$ & $0.116127^{*}$ & $0.043758^{*}$ & $0.058008^{*}$ \\
\hline & $(0.012647)$ & $(0.011661)$ & $(0.011584)$ & $(0.003518)$ & $(0.002359)$ & $(0.002924)$ \\
\hline \multirow[t]{2}{*}{$(1-a)$} & $0.918542^{*}$ & $0.924657^{*}$ & $0.926923^{*}$ & $0.883873^{*}$ & $0.956242^{*}$ & $0.941992^{*}$ \\
\hline & $(0.012647)$ & $(0.011661)$ & $(0.011584)$ & $(0.003518)$ & $(0.002359)$ & $(0.002924)$ \\
\hline Q1(4) & $326.39^{*}$ & $162.39^{*}$ & $90.175^{*}$ & 0.0026 & 0.0025 & 0.0024 \\
\hline Q1(8) & $482.09^{*}$ & $263.11^{*}$ & $158.89^{*}$ & 0.0052 & 0.0049 & 0.0047 \\
\hline Q2(4) & $38.485^{*}$ & $33.945^{*}$ & $31.662^{*}$ & 0.0022 & 0.0022 & 0.0022 \\
\hline Q2(8) & $39.551^{*}$ & $35.027^{*}$ & $32.720^{*}$ & 0.0045 & 0.0045 & 0.0045 \\
\hline Log Likelihood & 3861.589 & 3877.619 & 3889.840 & 5261.522 & 5069.878 & 5134.113 \\
\hline F Statistic & $36.02953^{*}$ & $31.22263^{*}$ & $29.47090^{*}$ & 0.000558 & 0.000559 & 0.000559 \\
\hline Probability & 0.0000 & 0.0000 & 0.0000 & 0.9812 & 0.9811 & 0.9811 \\
\hline
\end{tabular}

Robust Standard Errors are in Parenthesis. ${ }^{* *}$ indicates significant at $10 \%$ level, ${ }^{* *}$ indicates significant at $5 \%$ level and * indicates that at $1 \%$ level 


\section{Volatility forecasting}

\section{In-sample estimation accuracy}

To check whether the accuracy of volatility forecasting among the different models varied with distribution assumptions, we compared the log-likelihood, Schwarz Bayesian information criterion (SBC), and Akaike information criterion (AIC) for all of the models, estimating for whole-sample observations under normal and Student's $t$-error distribution. Table 7 shows the results. It is clear that the performance and goodness of fit of each model improved when Student's $t$-distribution was used for the residuals. This is because likelihood increased while both SBC and AIC decreased compared to when normal distribution was used for the residuals. Considering the Student's $t$-distribution for the residuals, a comparison of indicators reveals that among all of the models used for in-sample estimation, $\operatorname{AR}(2)-\operatorname{APARCH}(1,1)$ is the best since it has maximum likelihood and minimal SBC and AIC.

\section{Out-of-sample forecasting accuracy}

To check the forecasting accuracy of the models, we created a pseudo sample using the period from June 1, 2008 to December 31, 2012. All of the models were estimated for the pseudo sample period and then employed to estimate the variance in exchange rate returns for the period from January 1, 2013 to April 30, 2015. The forecasting performance of the models was compared on the basis of four different indicators under normal distribution and Student's $t$-distribution: root mean square error (RMSE), mean absolute error (MAE), mean absolute percent error (MAPE), and Theil inequality (TI).

Table 8 shows the comparative forecasting accuracy of the different models under normal and Student's $t$-distribution for the residuals. For the AR(2)$\operatorname{GARCH}(1,1)$ model, RMSE and TI decreased while MAE remained constant and MAPE increased when changing the distribution assumption. Thus, this model's forecasting accuracy was improved under Student's $t$-distribution. Likewise, the forecasting accuracy of $\operatorname{AR}(2)-\operatorname{IGARCH}(1,1)$ was improved with the above distribution (all of the four indicators decreased when Student's $t$-distribution was used). Meanwhile, $\operatorname{AR}(2)-\operatorname{APARCH}(1,1)$, which had the best in-sample estimation accuracy under Student's $t$-distribution, showed lower accuracy when such distribution was used for out-of-sample forecasting. Similarly, the forecasting accuracy of $\operatorname{AR}(2)$-EGARCH$(1,1)$ also became poor when Student's $t$-distribution was used;

Table 7 Comparison of models in within sample estimation accuracy

\begin{tabular}{lllllllll}
\hline Models & \multicolumn{3}{l}{ Normal distribution } & & \multicolumn{3}{l}{ Student's t-distribution } \\
\cline { 2 - 3 } & Log likelihood & SBC & AIC & & Log likelihood & SBC & AIC \\
\hline AR(2) - GARCH $(1,1)$ & 4087.309 & -4.5410 & -4.560 & & 6690.907 & -7.4044 & -7.4259 \\
AR(2) - APARCH $(1,1)$ & 4152.042 & -4.6056 & -4.6302 & & 7809.244 & -8.5490 & -8.5664 \\
AR(2) - EGARCH $(1,1)$ & 4087.921 & -4.5382 & -4.5596 & & 5213.334 & -5.7914 & -5.8160 \\
AR(2) - TARCH $(1,1)$ & 4145.995 & -4.6031 & -4.6245 & & - & & - & - \\
AR(2) - IGARCH $(1,1)$ & 3889.840 & -4.3294 & -4.3417 & & 5134.113 & -5.7155 & -5.730 \\
\hline
\end{tabular}


Table 8 Comparison of models in out of sample forecasting accuracy

\begin{tabular}{|c|c|c|c|c|c|c|c|c|}
\hline \multicolumn{3}{|c|}{$\operatorname{AR}(2)-\operatorname{GARCH}(1,1)$} & \multicolumn{2}{|c|}{$\operatorname{AR}(2)-\operatorname{APARCH}(1,1)$} & \multicolumn{2}{|c|}{$\operatorname{AR}(2)-\operatorname{EGARCH}(1,1)$} & \multicolumn{2}{|c|}{$\operatorname{AR}(2)-\operatorname{IGARCH}(1,1)$} \\
\hline & Normal & Student's $t$ & Normal & Student's $t$ & Normal & $\overline{\text { Student's } t}$ & $\overline{\text { Normal }}$ & $\overline{\text { Student's } t}$ \\
\hline RMSE & 0.0184 & 0.0183 & 0.0183 & 0.0187 & 0.0182 & 0.0185 & 0.0192 & 0.0183 \\
\hline MAE & 0.0093 & 0.0093 & 0.0094 & 0.0094 & 0.0093 & 0.0093 & 0.0110 & 0.0094 \\
\hline MAPE & 42.8555 & 43.5405 & 43.0390 & 43.1409 & 43.5094 & 42.8045 & 45.7949 & 43.7528 \\
\hline $\mathrm{Tl}$ & 0.6858 & 0.6436 & 0.6656 & 0.7243 & 0.6438 & 0.6951 & 0.7056 & 0.6496 \\
\hline
\end{tabular}

of the four indicators, one (MAE) remained constant while the other three (RMSE, MAPE, and TI) increased. Figures 4 and 5 in the Appendix show the forecasted volatility and confidence intervals for the above models, with the residuals following normal and Student's $t$-distribution.

\section{Conclusion}

Bangladesh, which the World Bank recently promoted from a low-income country to a lower-middle-income one, is moderately dependent on trade, but remittance holds high importance. In 2014, trade accounted for about 45\% of Bangladesh's GDP (about 55\% for other low-middle-income countries) while remittance accounted for $8.7 \%$ of the GDP (only $1.5 \%$ for other low-middle-income countries). Moreover, most exports from Bangladesh are destined for the US. Therefore, exchange rate volatility will have a significant effect on trade and remittance, and consequently on the whole economy. For this reason, it is extremely important to properly model and forecast exchange rate volatility. This study aimed to model the volatility of the taka-US dollar exchange rate return using daily observations over a span of 7 years. The leptokurtic fat-tailed nature of the exchange rate return series usually establishes a rationale for using skewed distribution-such as Student's $t$-rather than normal distribution to estimate volatility models. The main focus was on whether the same nature exists in the taka-US dollar exchange rate return and whether the results were improved with Student's $t$-distribution. In particular, this study tried to model the volatility dynamics of the taka-US dollar exchange rate return using GARCH, APARCH, EGARCH, TGARCH, and IGARCH models. The findings from the models were compared under the regular normal distribution assumption for the residuals against Student's $t$-distribution. All of the models successfully passed the diagnostic tests when Student's $t$-distribution was used for the residuals. Further, in-sample estimation accuracy was observed to be improved when such a distribution was used. For modeling in-sample volatility dynamics, $\operatorname{AR}(2)-\operatorname{IGARCH}(1,1)$ was found to be the most accurate. We also tried to find the appropriate model for volatility forecasting, and we found that the forecasting accuracy of $\operatorname{AR}(2)-\operatorname{GARCH}(1,1)$ and $\operatorname{AR}(2)-\operatorname{IGARCH}(1,1)$ was improved with Student's $t$-distribution against normal distribution. However, in terms of out-of-sample forecasting accuracy, $\operatorname{AR}(2)-\operatorname{GARCH}(1,1)$ is considered the best compared to $\operatorname{AR}(2)-\operatorname{IGARCH}(1,1)$ since MAE, MAPE, and TI were all observed to be lower for the former model. That said, the issue of structural change presents a potential limitation of this exercise. During the data span, however, there was no regime shift in exchange rates, which minimizes its likelihood. 


\section{Endnotes}

1"Volatility clustering," as defined by Mandelbrot (1963), refers to a situation where large changes tend to be followed by large changes, and small changes tend to be followed by small changes.

${ }^{2}$ There is a negative correlation between current return and future volatility (Black, 1976). This means that increased volatility for "bad news" will be more so in relation to "good news." This typical phenomenon in financial data is popularly known as the "leverage effect."

${ }^{3}$ The standard errors of the TGARCH model with Student's $t$-distribution as the assumption for the errors are not well defined in EViews 9, which restricts its application here.

\section{Appendix}

Table 9 Stionarity test results for the exchange rate return series

\begin{tabular}{|c|c|c|c|c|c|c|c|}
\hline \multicolumn{4}{|c|}{$\begin{array}{l}\text { Augmented Dickey Fuller (ADF) test } \\
\text { HO: exchange rate return has a unit root }\end{array}$} & \multicolumn{4}{|c|}{$\begin{array}{l}\text { Kwiatkowsk -Philips-Schmidt-Shin (KPSS) test } \\
\text { HO: exchange rate return is stationary }\end{array}$} \\
\hline \multicolumn{2}{|l|}{ Intercept } & \multicolumn{2}{|c|}{ Trend and intercept } & \multicolumn{2}{|c|}{ Intercept } & \multicolumn{2}{|c|}{ Trend and intercept } \\
\hline $\begin{array}{l}\text { Test } \\
\text { statistic }\end{array}$ & Probability & $\begin{array}{l}\text { Test } \\
\text { statistic }\end{array}$ & Probability & $\begin{array}{l}\text { Test } \\
\text { statistic }\end{array}$ & $\begin{array}{l}1 \% \text { critical } \\
\text { value }\end{array}$ & $\begin{array}{l}\text { Test } \\
\text { statistic }\end{array}$ & $\begin{array}{l}1 \% \text { critical } \\
\text { value }\end{array}$ \\
\hline-14.9439 & 0.000 & -14.9552 & 0.000 & 0.4630 & 0.7390 & 0.1913 & 0.2160 \\
\hline
\end{tabular}

Table 10 Skewness and Kurtosis of exchange rate return

\begin{tabular}{lll}
\hline Variable & Skewness & Kurtosis \\
\hline Exchange Rate Return & 3.6624 & 62.8792 \\
\hline
\end{tabular}

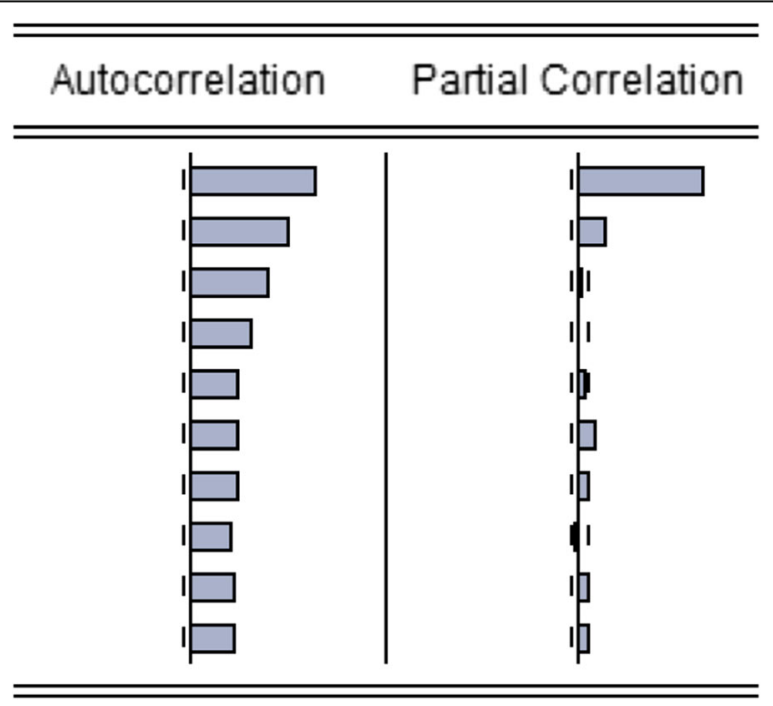

Fig. 1 Correlogram of exchange rate return 


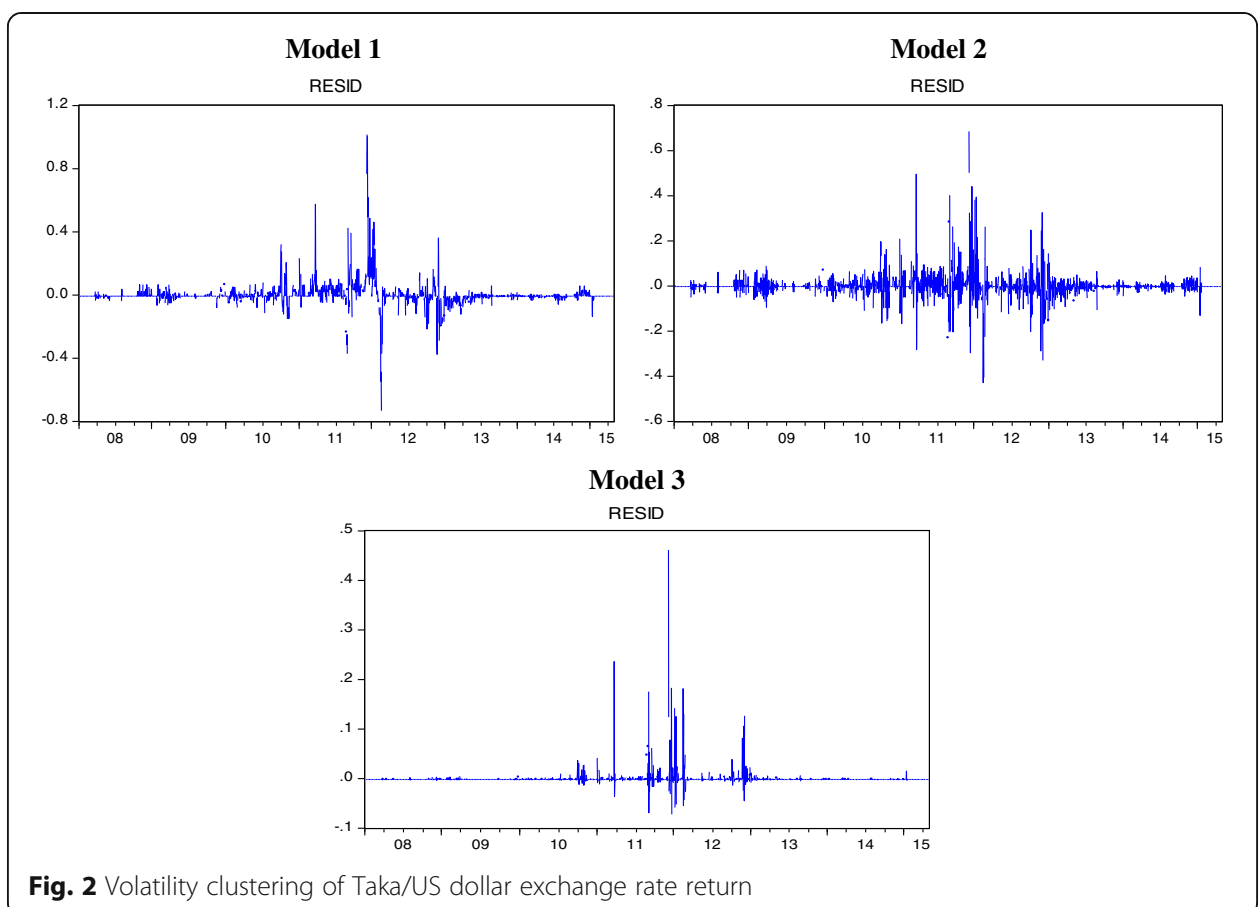

Fig. 2 Volatility clustering of Taka/US dollar exchange rate return
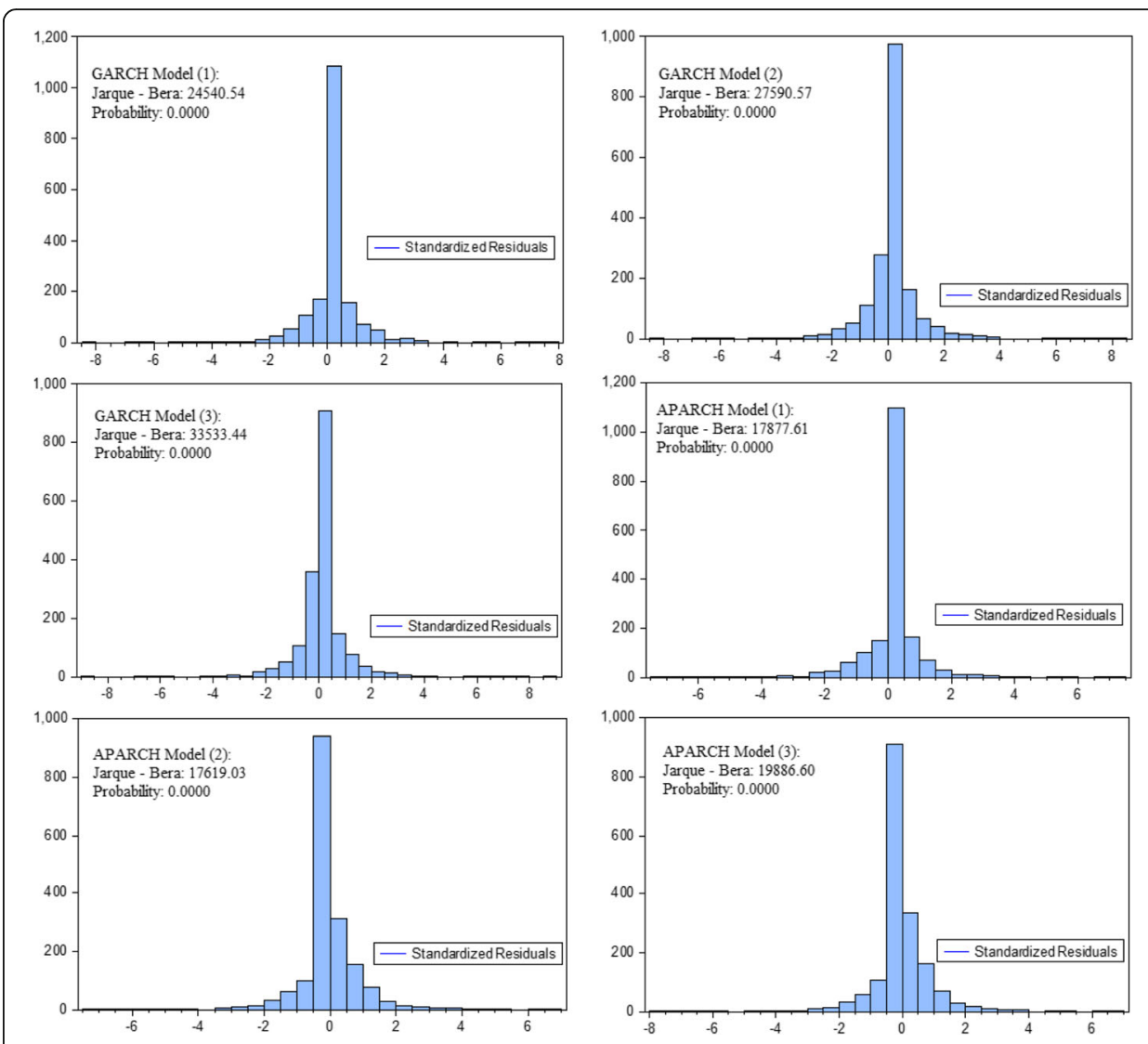

Fig. 3 Distribution of the error term in different models in Table 2 


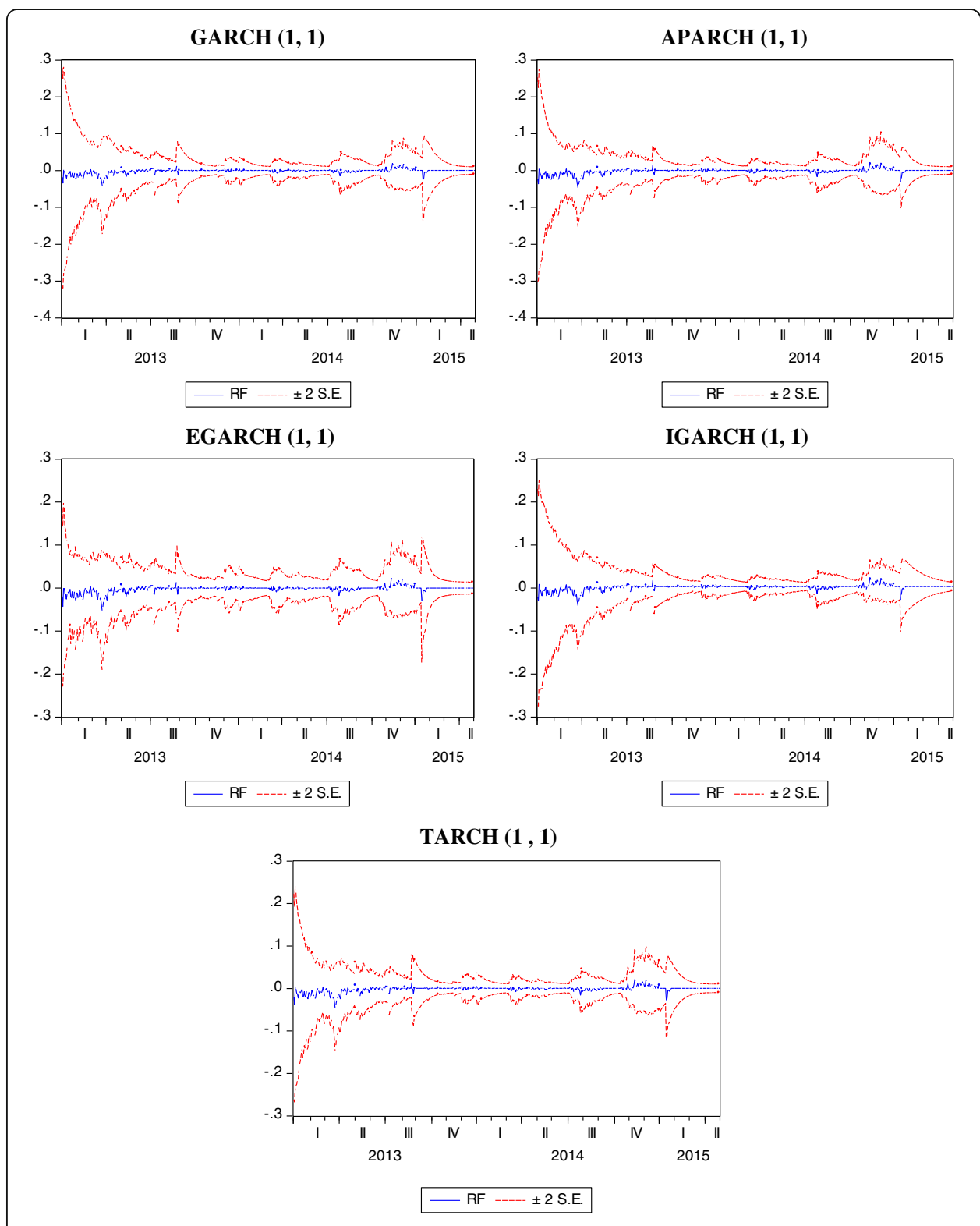

Fig. 4 Volatility forecasting with normal distribution 

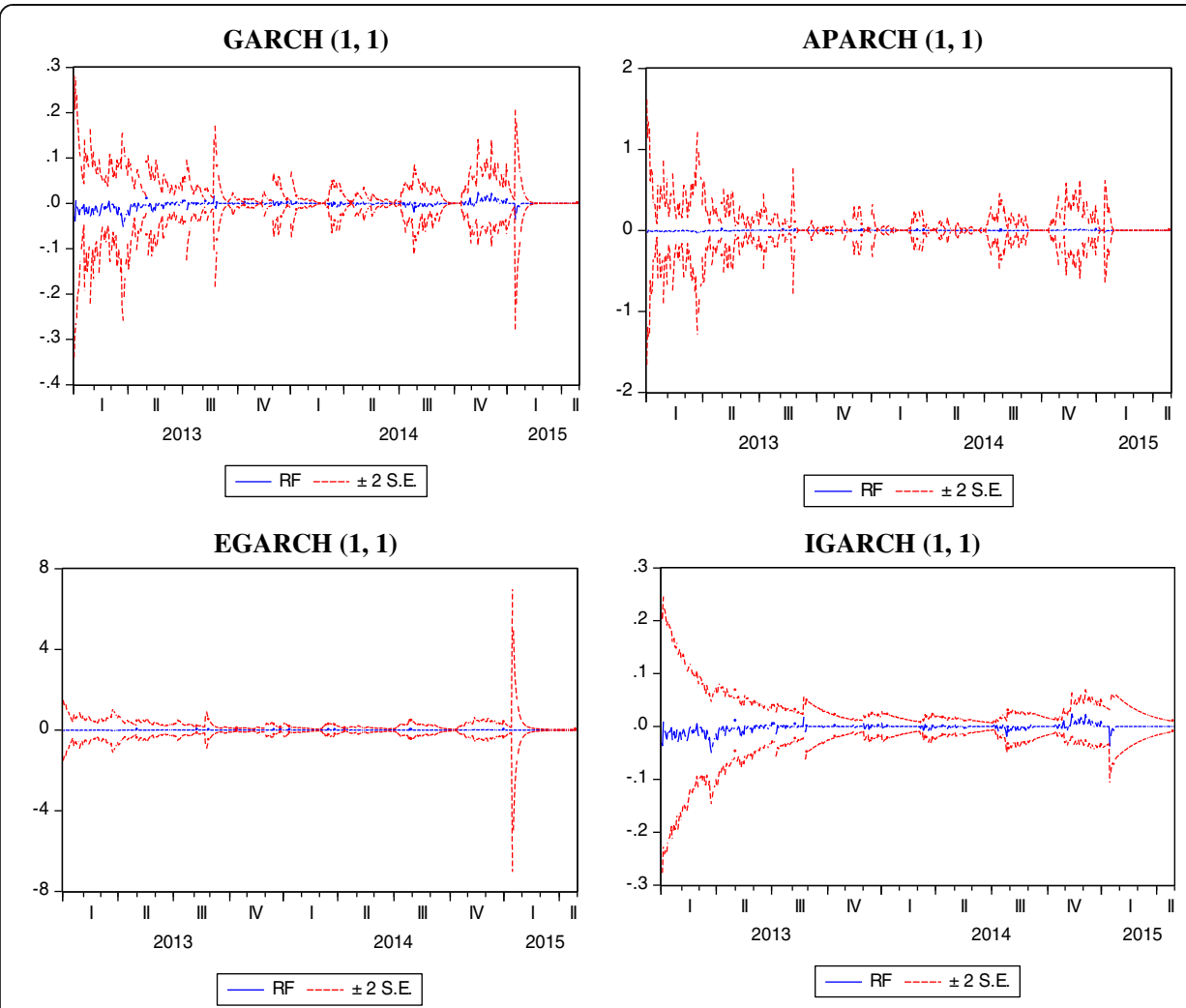

Fig. 5 Volatility forecasting with Student's - t distribution

\section{Acknowledgements}

Authors are indebted to Dr. Ummul Hasanath Ruthbah, Associate Professor, Department of Economics, University of Dhaka for the valuable comments and guidance on the way of completion of the exercise.

\section{Authors' contributions}

All the authors in the current work have contributed uniformly. SMA developed the research problem formulated the model design and performed the econometric exercise. SS took the responsibility to do the survey of existing literature and finding the research gap and contributed to the result explanations. MSHS and NH synthesized research gap with the methodology and have given effort to bring the issue into perspective and contributed to prepare the draft. All authors have read and approved the manuscript.

\section{Competing interests}

The authors declare that they have no competing interests.

\section{Publisher's Note}

Springer Nature remains neutral with regard to jurisdictional claims in published maps and institutional affiliations.

\section{Author details}

${ }^{1}$ Department of Economics, University of Dhaka, Dhaka, Bangladesh. ${ }^{2}$ Department of Development Studies, University of Dhaka, Dhaka, Bangladesh. ${ }^{3}$ University of Manchester, Manchester, UK.

Received: 18 July 2017 Accepted: 29 September 2017

Published online: 05 October 2017

\section{References}

Alam MZ, Rahman MA (2012) Modelling volatility of the BDT/USD exchange rate with GARCH model. Int J Econ Finance 4(11):193

Alexander SS (1961) Price movements in speculative markets: trends or random walks. Ind Manage Rev (pre-1986) 2(2):7 
Andersen TG, Bollerslev T (1998) Answering the skeptics: Yes, standard volatility models do provide accurate forecasts. Int Econ Rev 39(4):885-905

Asseery A, Peel DA (1991) The effects of exchange rate volatility on exports: some new estimates. Econ Lett 37(2):173-177 Bala DA, Asemota JO (2013) Exchange-rates volatility in Nigeria: application of GARCH models with exogenous break. CBN J Appl Stat, 4(1):89-116

Black F (1976) Studies of Stock Market Volatility Changes, Proceedings of the 1976 Meeting of the American Statistica Association. In Business and Economic Statistics Section, Vol 177. American Statistical Association, Alexandria, p 181

Bollerslev T (1986) Generalized autoregressive conditional heteroskedasticity. J Econ 31(3):307-327

Bollerslev T (1987) A conditionally heteroskedastic time series model for speculative prices and rates of return. Rev Econ Stat, 69(3):542-547

Bollerslev T, Chou RY, Kroner KF (1992) ARCH modeling in finance: a review of the theory and empirical evidence. J Econ 52(1-2):5-59

Brooks C, Burke SP (1998) Forecasting exchange rate volatility using conditional variance models selected by information criteria. Econ Lett 61(3):273-278

Cağlayan E، Ün AT Dayıoğlu T (2013) Modelling Exchange Rate Volatility in MIST Countries. Int J Bus Soc Sci, 4(12):260-269

Choo WC, Loo SC, Ahmad MI (2002) Modelling the volatility of currency exchange rate using GARCH model. Pertanika J Soc Sci Humanit 10(2):85-95

Clement A, Samuel A (2011) Empirical modeling of Nigerian exchange rate volatility. Math Theory Model, Vol.1, No.3

De Grauwe P (1988) Exchange rate variability and the slowdown in growth of international trade. Staff Pap Int Monetary Fund, 35(1):63-84

Dhamija AK, Bhalla VK (2010) Financial time series forecasting: comparison of various arch models. Glob J Finance Manag 2(1):159-172

Diebold FX, Nerlove M (1989) The dynamics of exchange rate volatility: a multivariate latent factor ARCH model. J Appl Econ 4(1):1-21

Ding Z, Granger CW, Engle RF (1993) A long memory property of stock market returns and a new model. J Empir Financ 1(1):83-106

Engle RF (1982) Autoregressive conditional heteroscedasticity with estimates of the variance of United Kingdom inflation. Econometrica J Econometric Soc, 50(4):987-1007

Glosten LR, Jagannathan R, Runkle DE (1993) On the relation between the expected value and the volatility of the nominal excess return on stocks. J Financ 48(5):1779-1801

Hakkio CS (1984) Exchange rate volatility and federal reserve policy. Econ Rev, (Jul), 18-31. https://www.kansascityfed. org/publicat/econrev/EconRevArchive/1984/3q84hakk.pdf

Hansen PR, Lunde A (2005) A forecast comparison of volatility models: does anything beat a GARCH $(1,1)$ ? J Appl Econ 20(7):873-889

Herwartz H, Reimers HE (2002) Empirical modelling of the DEM/USD and DEM/JPY foreign exchange rate: Structural shifts in GARCH-models and their implications. Appl Stoch Model Bus Ind 18(1):3-22

Longmore R, Robinson W (2004) Modelling and forecasting exchange rate dynamics: an application of asymmetric volatility models. Bank Jam Working Pap WP2004/03. http://www.boj.org.jm/uploads/pdf/papers_pamphlets/ papers_pamphlets_modelling_and_forecasting_exchange_rate_dynamics_an_application_of_aysmmetric_ volatility_models.

Mandelbrot B (1963) The variation of certain speculative prices. J Bus 36:394-419

Nelson DB (1991) Conditional heteroskedasticity in asset returns: a new approach. Econometrica J Econometric Soc 59(2):347-370

Pelinescu E (2014) Volatility analysis of the Romanian exchange rate.Procedia Economics and. Finance 8:543-549

Ramasamy R, Shanmugam Munisamy D (2012) Predictive accuracy of GARCH, GJR and EGARCH models select exchange rates application. Glob J Manag Bus Res, 12(15):89-100

Rofael D, Hosni R (2015) Modeling exchange rate dynamics in Egypt: observed and unobserved volatility. Mod Econ 6(01):65

Tse YK (1998) The conditional heteroscedasticity of the yen-dollar exchange rate. J Appl Econ 13(1):49-55

Vee DC, Gonpot PN, Sookia N (2011) Forecasting volatility of USD/MUR exchange rate using a GARCH $(1,1)$ model with GED and Student'st errors. University Mauritius Res J 17(1):1-14

Zakoian JM (1994) Threshold heteroskedastic models. J Econ Dyn Control 18(5):931-955

\section{Submit your manuscript to a SpringerOpen ${ }^{\circ}$} journal and benefit from:

- Convenient online submission

- Rigorous peer review

- Open access: articles freely available online

- High visibility within the field

- Retaining the copyright to your article

Submit your next manuscript at $>$ springeropen.com 